\title{
Personnel' attitudes in the educational organizations toward governance norms in countryside Sharkia and Sohag governorates, Egypt
}

\author{
Salem S. M. A. , Khalifa I. A. A., Abdelsalam M. F. S. \\ Department of Agricultural Extension and Rural Sociology, Faculty of Agriculture, Al-Azhar University, Assiut, Egypt
}

\begin{abstract}
The research aimed to measure the attitudes of employees in educational organizations towards governance standards in the countryside of Sharkia and Sohag governorates, and this goal was achieved through: (1) Determine the standards of governance for educational organizations, (2) measuring the respondents' attitudes towards governance standards, (3) Determine the level of respondents' attitudes towards implementing Governance within their organizations, (4) Determine the correlation between the level of the respondents' trends and their independent variables. The research was conducted on a sample of workers in the countryside of Sharkia and Sohag governorates, amounting to 200 respondents. The Zagazig and Minya Al-Qamh centers were selected in Sharkia Governorate, Sohag and Gerga centers were selected in Sohag Governorate, the two largest villages were selected from each center, and an organization was selected from each village. Data were collected by interview using a questionnaire form, and data were collected during the months of June, July and August 2021 by personal interview. Frequencies, percentages, and figures were used to display the data, and the weighted average and (Seberman) correlation coefficient was used to analyze the relationship between the respondents' level of attitude and independent variables, and this was done using the statistical software for social sciences (SPSS). The most important results:

- The low level of tendency towards governance standards in the two governorates' countryside, especially: accountability $(70.0 \%)$, transparency $(62.5 \%)$, reliance on the rule of law $(60.5 \%)$, and responsiveness and consensus around community interests $(57.5 \%)$.

- $\quad$ The respondents' attitude level was moderate in efficiency and effectiveness (55.5\%), equality (58.5\%), and participation $(46.5 \%)$.

- The criteria can be arranged in descending order: efficiency and effectiveness (1.69\%), participation $(1.65 \%)$, equality $(1.60 \%)$, responsiveness and consensus around the interests of society $(1.46 \%)$ and based on the rule of law (1.43\%), transparency (1.62\%), and accountability $(1.35 \%)$.

- There is a correlation between the respondents' attitude towards applying governance standards and the studied independent variables such as: leadership level, job satisfaction, openness to the outside world, and level of ambition at levels $0.05,0.01$.
\end{abstract}

Keywords: personnel' attitudes, educational organizations, governance, governance norms, Sohag, Sharkia.

\footnotetext{
* Corresponding author: Salem S. M. A.,

E-mail address: samymahmoud.a80@gmail.com
} 


\title{
اتجاهات العاملين بالمنظمات التعليمية نحو معايير الحوكمة بريف محافظتي الثرقية وسو هاج بجمهورية مصر العربية العربية
}

\author{
سامي محمود أحمد سالم ، إير اهيم عبد الرحمن علي خليفة ، محمد فوزي سالمان عبد السلام \\ قسم الارشاد الزر اعى والمجتمع الريفي ، كلية الزراعة ، جامعة الأزهر (فرع أسيوط) ، أسيوط ، جمهورية مصر العربية
}

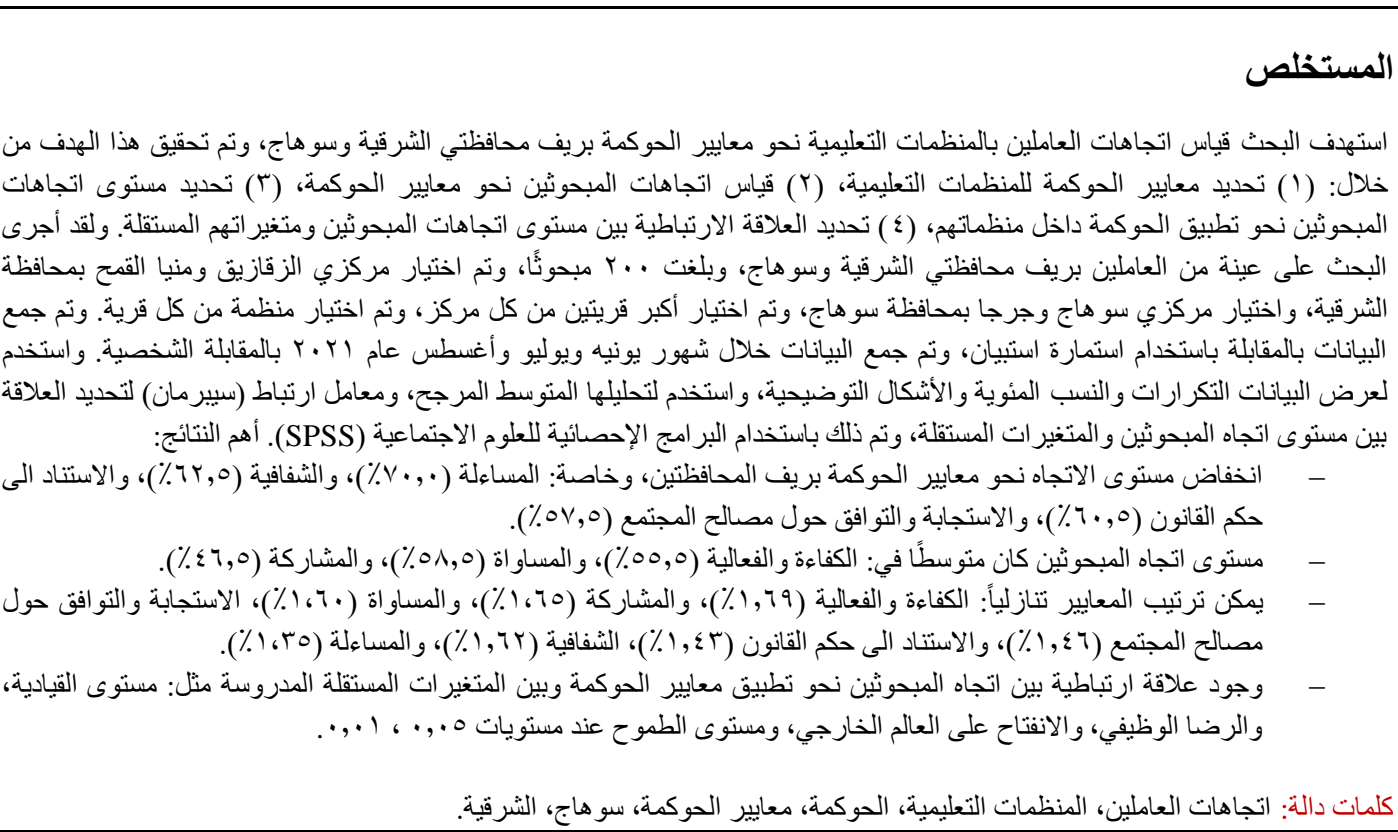




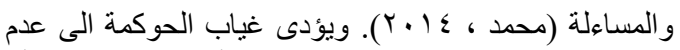

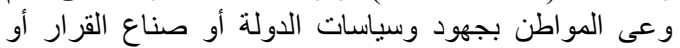

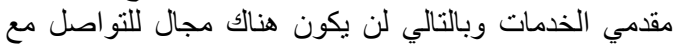

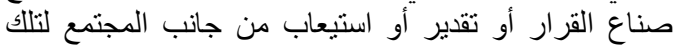

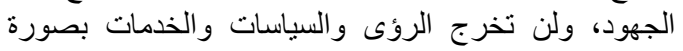

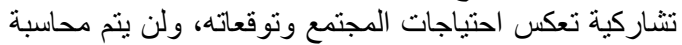

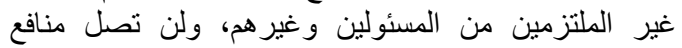
الخدمات والسياسات بصورة كاملة وفعالة لكافة شرئ وائح المجتمع وخاصة الفقر اء و غير القادرين وبالتالي سيكون هنالك وفئة

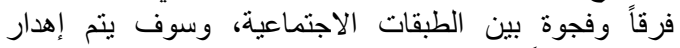

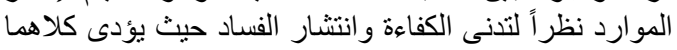

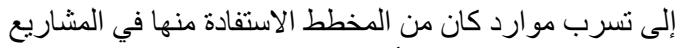

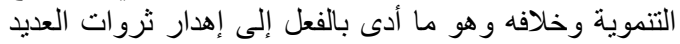

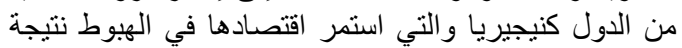

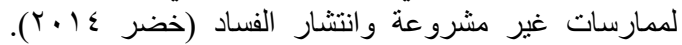
وتعتبر الحوكمة من الأساليب التنظيمية الحديثة في الإدارة

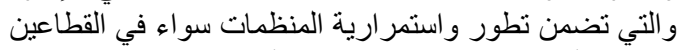

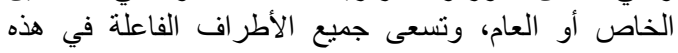

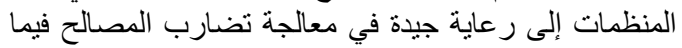
بينها وتعتبر المنظمات التعليمية كغير ها من المنظمات ملئ ملزمة فئة

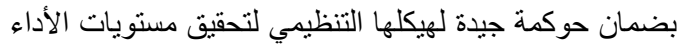

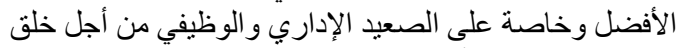

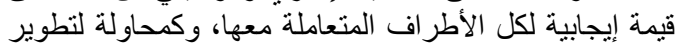

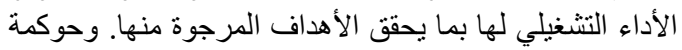

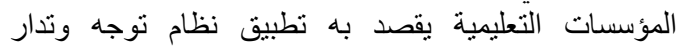

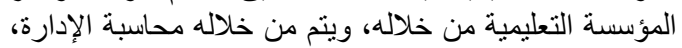

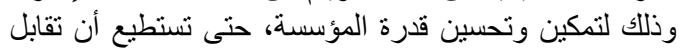

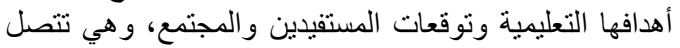

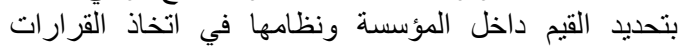

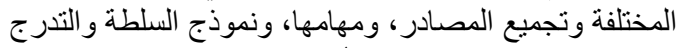
الهرمي، وعلاقاتها كمؤسنة بالعالم الأكاديمي (Hallak and Poisso, 2006).

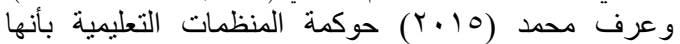

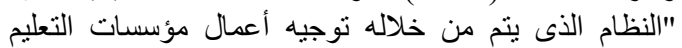

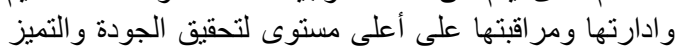

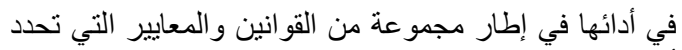

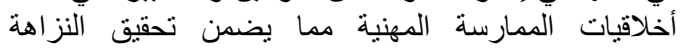

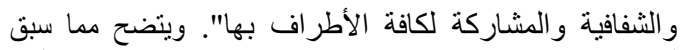
أهمية تطبيق الحوكمة بالمنظمات التعليمية لضمان تحقيق مستوى أداء جيد لتلك المؤسسات من خلال تحسين القدرات الخاصة بالهين بالهيكل

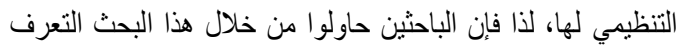

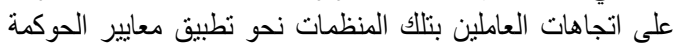

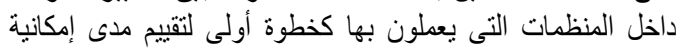

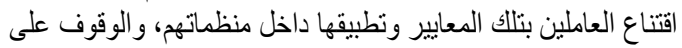

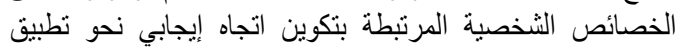
معايير الحوكمة.

\section{مقدمة ومشكلة البحث}

ترجع كلمة حوكمة في الأصل للتعبير عن قدرة رُبًان السفينة

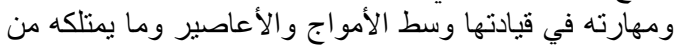

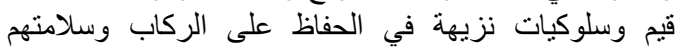

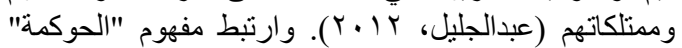

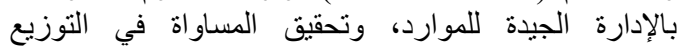

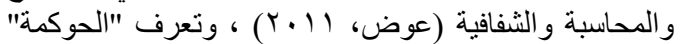

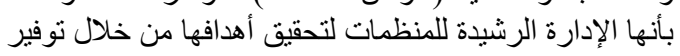

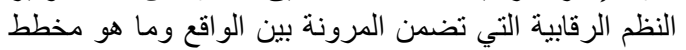

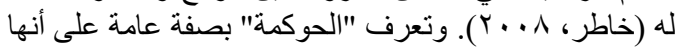

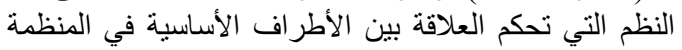

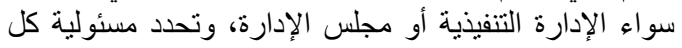

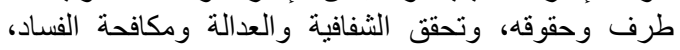

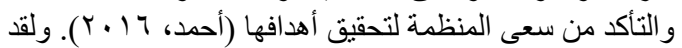

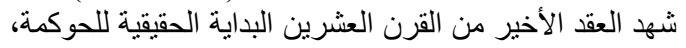

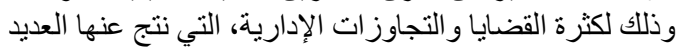

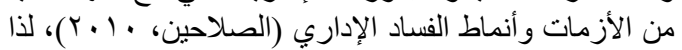

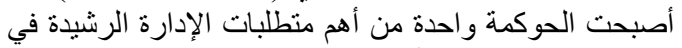

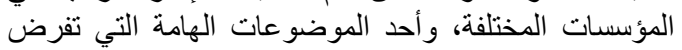
نفسها على جدول أعمال المؤسسات و المنظمات الدوات الدولية

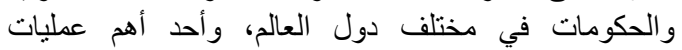

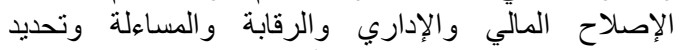

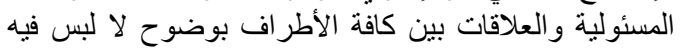

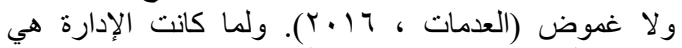

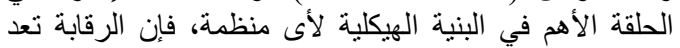

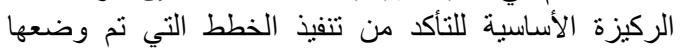

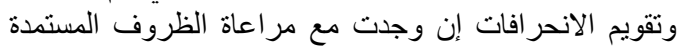

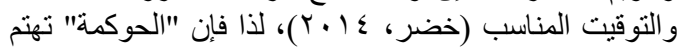

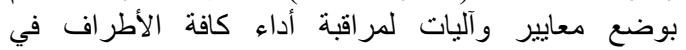

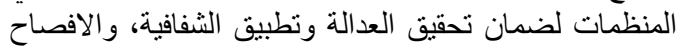
عن المعلومات، وتعزيز عملية الثقة والمصداقية في في بيئة

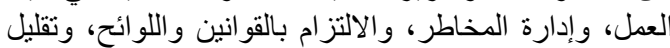

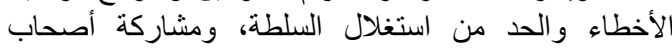

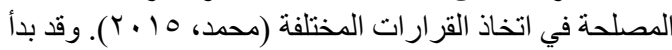

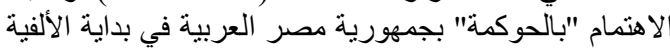

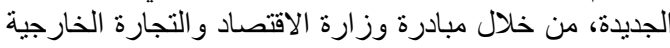

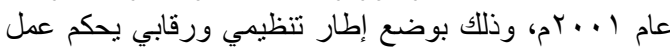

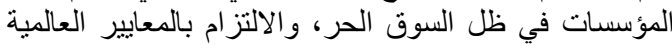

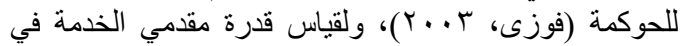

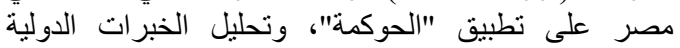

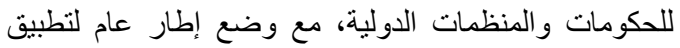

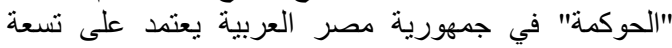

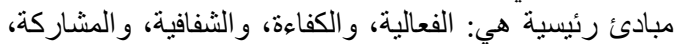

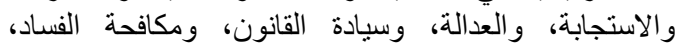




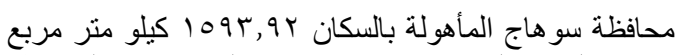

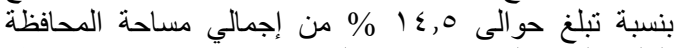

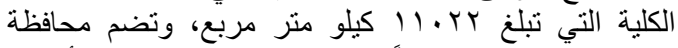

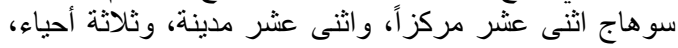

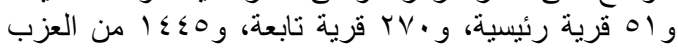

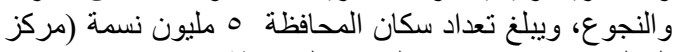

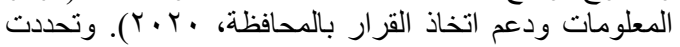

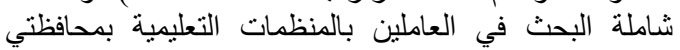

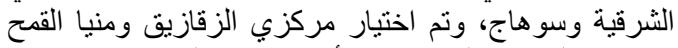

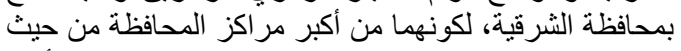

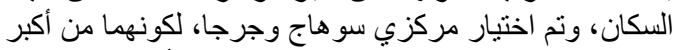

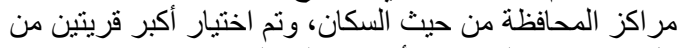

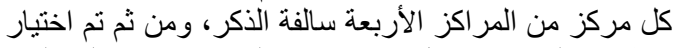

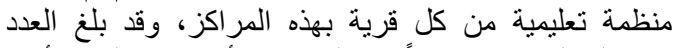

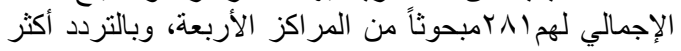

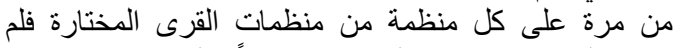

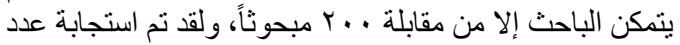

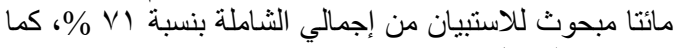

هو مبين بالجدول (1).

\section{طريقة جمع البيانات}

استخدمت استمارة الاستبيان كأداة لجمع البيانات بالمقابلة

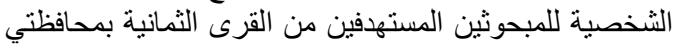

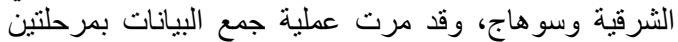
أساسيتين:

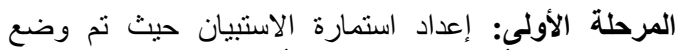

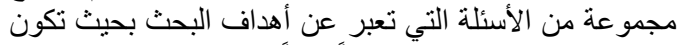
عبار اتها و اضحة ونه الاسلة ومعبرة تعبير آ دقيقاً عنها.

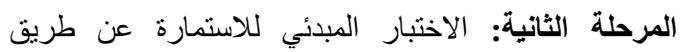

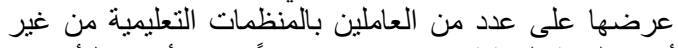

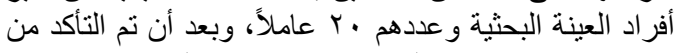

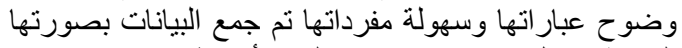

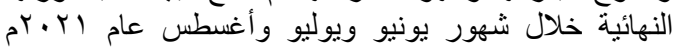
بالمقابلة الشخصية للمبحوثين. وقد اشتملت الثئ استمارة الاستبيان

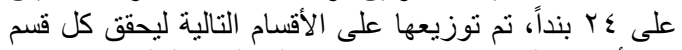
منها أهداف البحث، وكان توزئ توزيعها على النحو التالي:

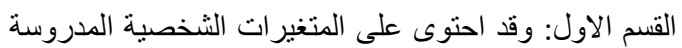

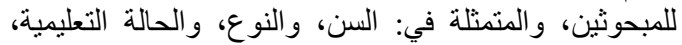

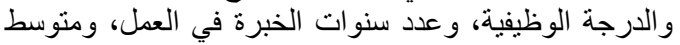

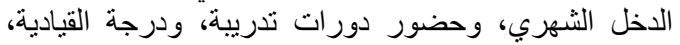

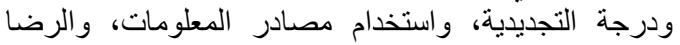

الوظيفي، والانفتاح على العالم الخارجي، ومستوى الطموح.

القسم الثاني : ويختص باتجاهات العاملين بالمنظمات التعليمية

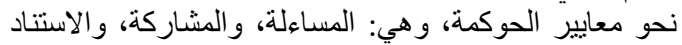

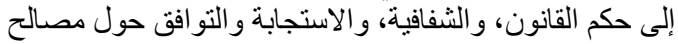

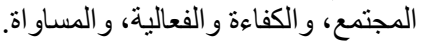

أهداف البحث

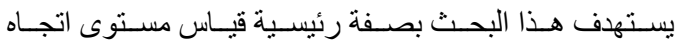

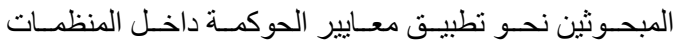

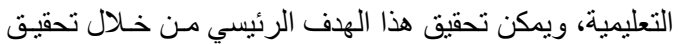
مجموعة من الأهداف الفرعية ولنية التالية:

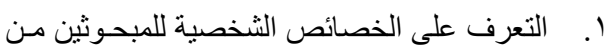

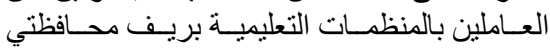
الثرقية وسو هاج.

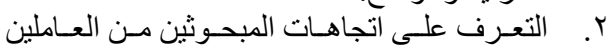

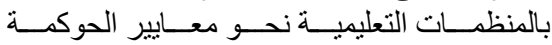

المدروسة.

r. تحديد العلاقة الارثباطيـة بـين اتجاهـات المبحوثين

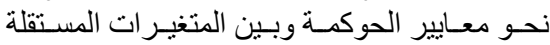

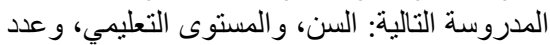

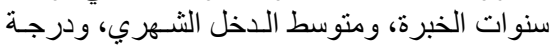

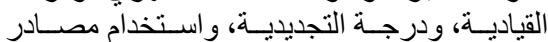

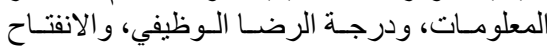
على العالم الخارجي، ومستوى الطموح.

\section{الفرض الإحثي}

لتحقيق الهدف الثالث تم صباغة الفرض البحثي التالي: "توجد

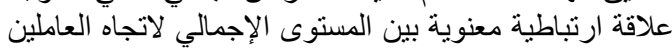

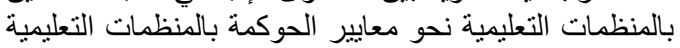

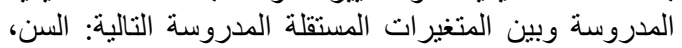
و المستوى التعليمي، و عدد سنوات الخبرة، ومتوسط التئ الدخل

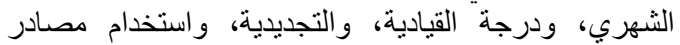

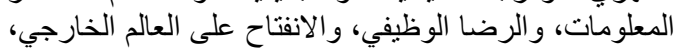

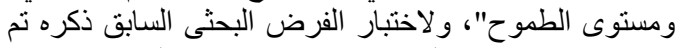

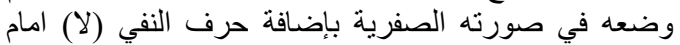

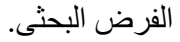

\section{الطريقة البحثية}

أُجرى هذا البحث بمحافظتي الشرقية وسوهاج؛ حيث تعتبر

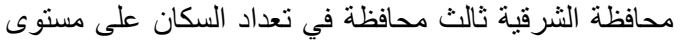

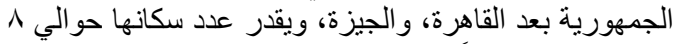

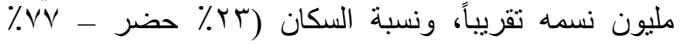

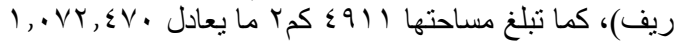

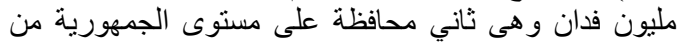

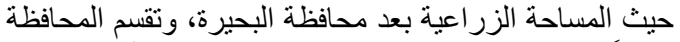

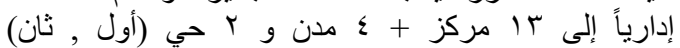

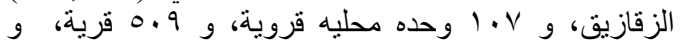

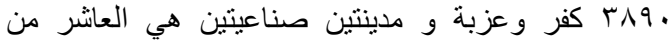

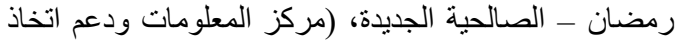

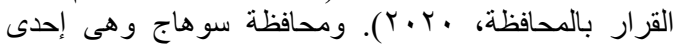

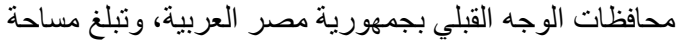


Salem et al. / Archives of Agriculture Sciences Journal 4(2) 48-60, 2021.

جذول (1) ) شاملة و عينة البحث بالمنظمات التعليمية بالقرى المختارة.

\begin{tabular}{|c|c|c|c|c|}
\hline الإجمالي & المبحوثين & القرية & المركز & لمحافظة \\
\hline$\varepsilon$ & $r \cdot$ & زنكلون & \multirow{2}{*}{ الزقازيق } & \multirow{4}{*}{ الثرقية } \\
\hline 0. & Tr & رزان & & \\
\hline$\varepsilon r$ & $r$. & بندف & \multirow{2}{*}{ منيا القمح } & \\
\hline$r \cdot$ & 11 & العز ازية & & \\
\hline 174 & $1 \ldots$ & \multicolumn{3}{|c|}{ مجموع المحافظة } \\
\hline rA & ro & بلصفورة & \multirow{2}{*}{ سوهاج } & \multirow{4}{*}{ سو هاج } \\
\hline Tr & ro & الكو امل & & \\
\hline rq & $r$. & الخلفية & \multirow{2}{*}{ جرجا } & \\
\hline$r$. & $r \cdot$ & بيت داوود & & \\
\hline 119 & $1 \ldots$ & \multicolumn{3}{|c|}{ مجموع المحافظة } \\
\hline rNI & $r \ldots$ & \multicolumn{3}{|c|}{ المجموع الكلي } \\
\hline
\end{tabular}

المصدر : مركز المعلومات ودعم اتخاذ القرار، بالمحافظتين.

تقسيم المبحوثين إلى فئتين (نعم، و ولا)، واعطيت الدرجات (r، ( ) على الترتيب.

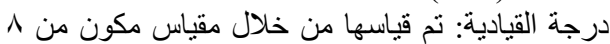

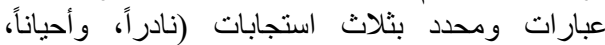

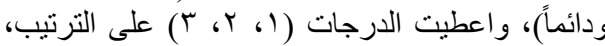

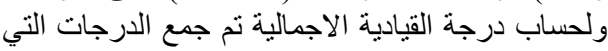

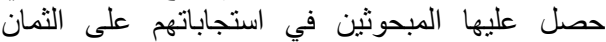
عبارات، وتم تقسيم المبحوثين إلى ثناثلاث فئات وهي:

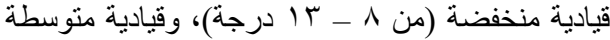

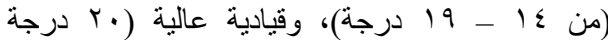

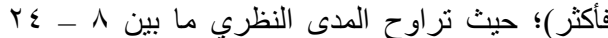

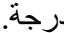

درجة التجديدية: تم قياسها من خلال مقياس مكون من 9

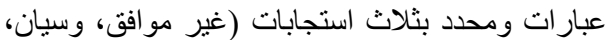

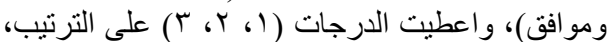

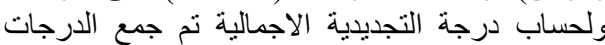

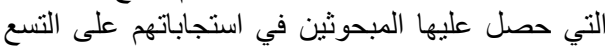

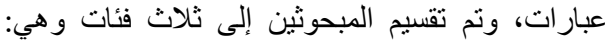

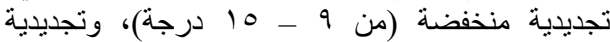

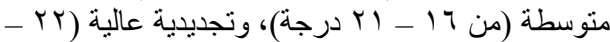

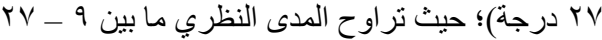

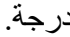

•1. استخدام مصادر المعلومات: تم قياسه من خلال مقياس

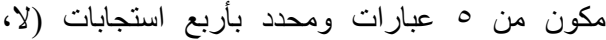

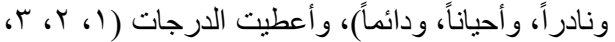

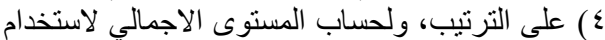

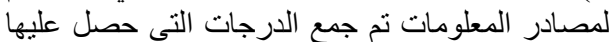

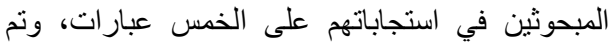

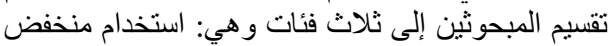

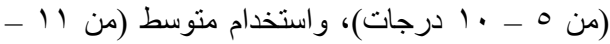

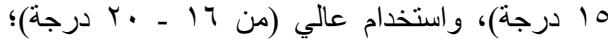

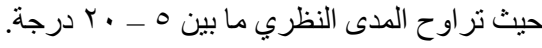

المعالجة الكمية للبيانات

بعد اتمام عملية جمع البيانات نم تكويدها ومعالجتها كمياً على ي. النحو التالي: - النيام

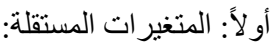

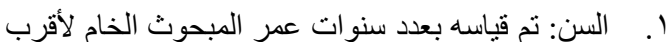

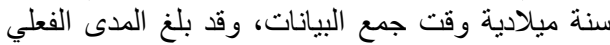

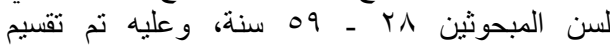

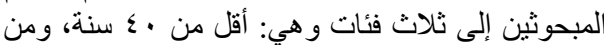

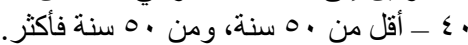
Y. وتم تقسيم المبحوثين إلى ذكور (درجنان) و إناث (درجة و احدة).

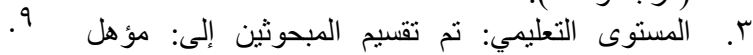

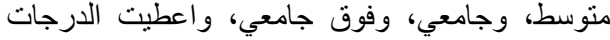

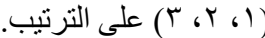

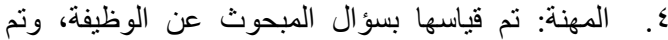

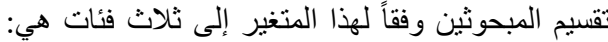

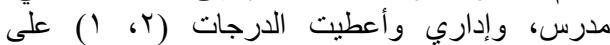
الترتيب.

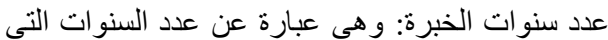

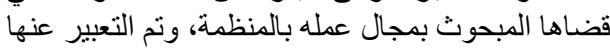

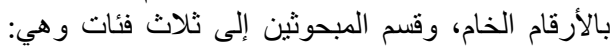

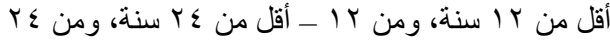

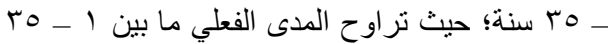

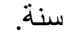
7. . متوسط الدخل الثهري: تم التعبير عنه بالرقم الخام،

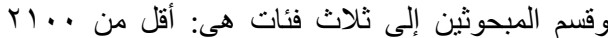

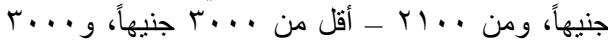

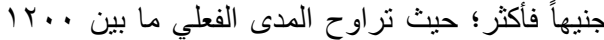

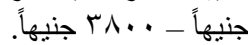

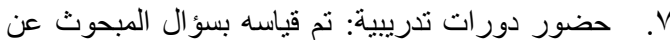
حضوره دورات تدريبية تتعلق بمعايير الحوكمة، وتئن 
المعايير الخمسة الفرعية المكونة للمعيار الرئيسي، وتم تقسيم

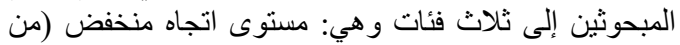
ro - 10

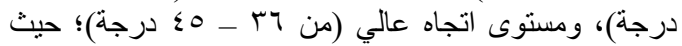

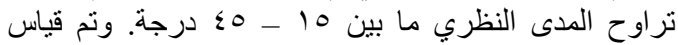

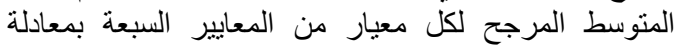
المتوسط المرجح كالتالي:

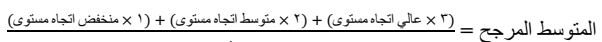

' . معيار المساءلة: وتكون المعيار من خمسة معايير فرعية

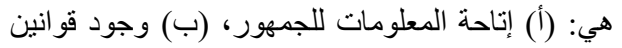

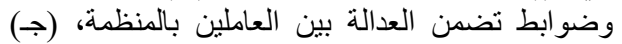

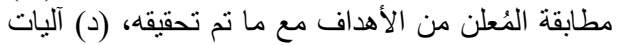

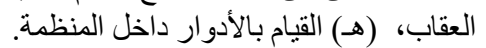

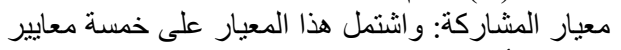

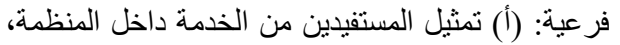

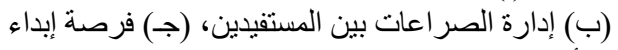

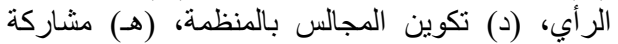

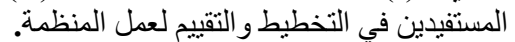

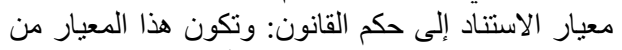

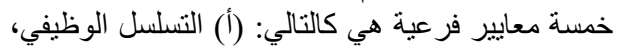

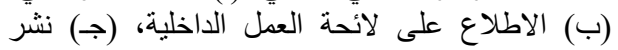

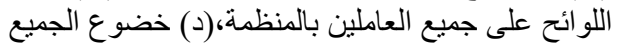

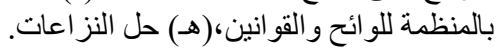

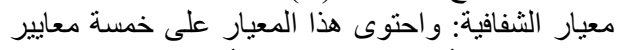

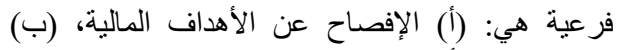

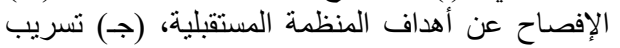

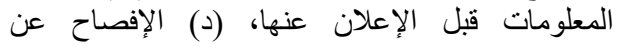

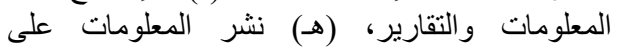
الانترنت.

معيار الاستجابة والتوافق حول مصالح المجتمع: وتكون

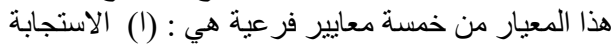

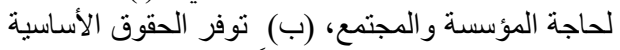

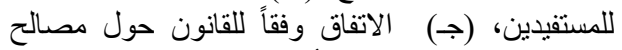

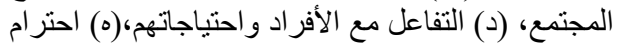
الحقوق القانونية.

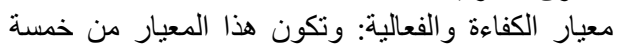

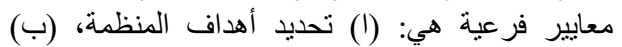

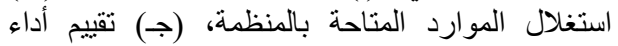

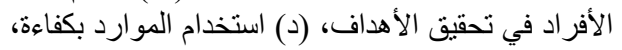

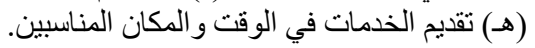

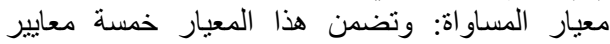

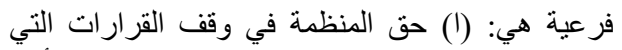

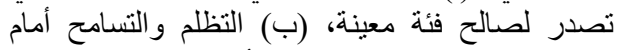

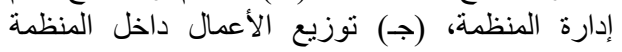

ا1 ـ درجة الرضا الوظيفي: تم قياسها من خلال مقياس مكون

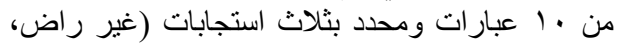

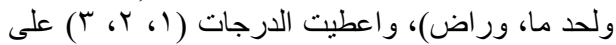

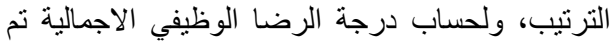

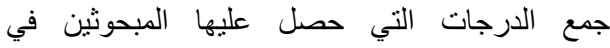
استجاباتهم على العشر عبار ات, وتم تقات تقيم المبحوثين

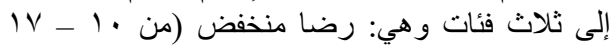

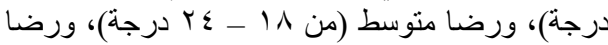

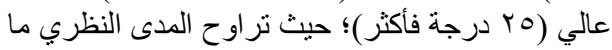

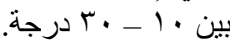
r ا. الانفتاح على العالم الخارجي: تم قياسه من خلادل مقياس

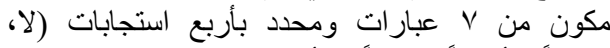

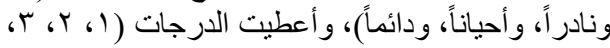

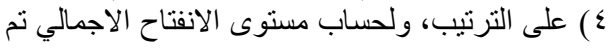

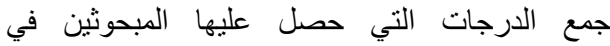

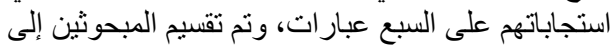

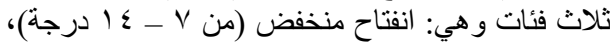

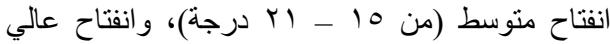

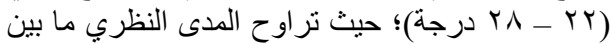

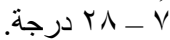

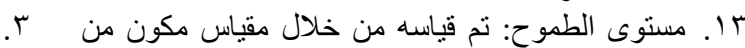

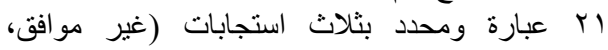

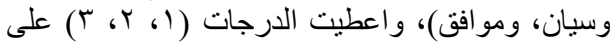

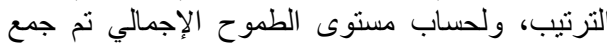
الدرجات التي حصل عليها المبحوثين في استجاباتهم الإني على الإحدى و عشرون عبارة، وتم تقسيم المبحوثين إلى الى الى

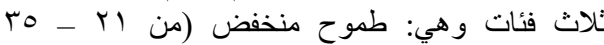

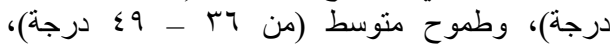

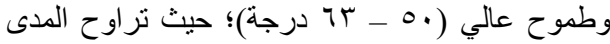

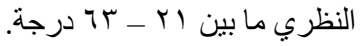

ثانياً: المتغير التابع: اتجاهات العاملين نحو معايير الحوكمة: تم قياسه من خلال مقياس مكون من 0 ـ 1 عبارة ومحدد بثلاث

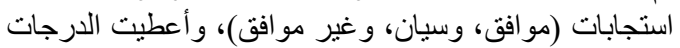

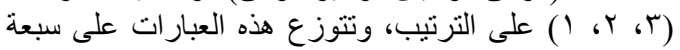

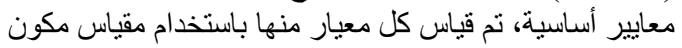

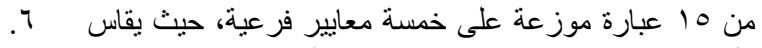

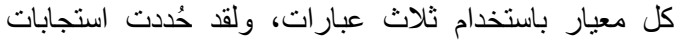

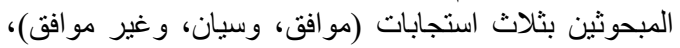

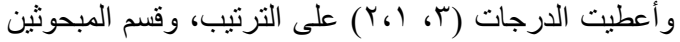
إلى ثلاث فئات و هي: اتجاه منخفض (r ( -

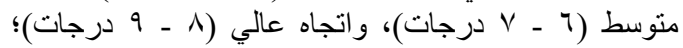

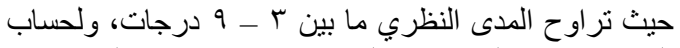

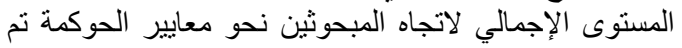
جمع الدرجات التي حصل عليها المبحوثين في اتجاهاتهم نحو لإني التين 


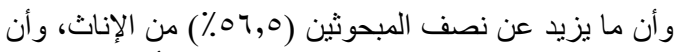

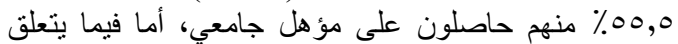

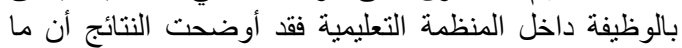

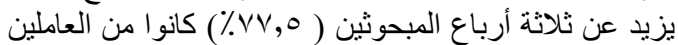

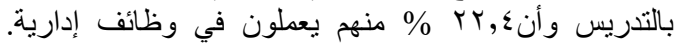

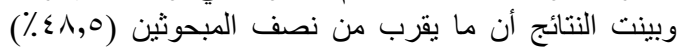

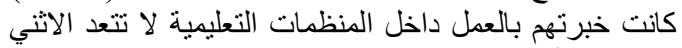

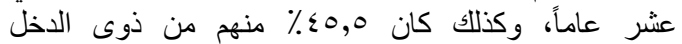

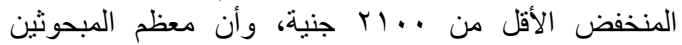

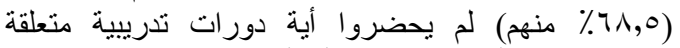

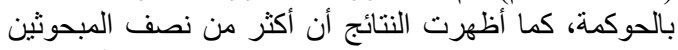

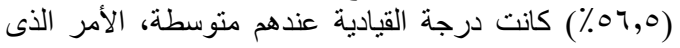

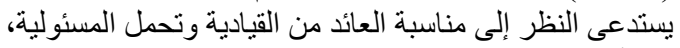

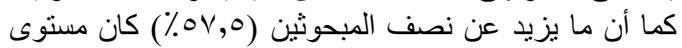

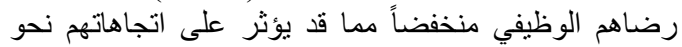

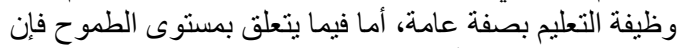

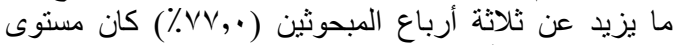
طموحهم متوسطاً في تلك الوظيفة.
بالتساوي، (د) التعامل مع المو اطنين برفق، (هـ) الترفع

عن المصالح الثخصية.

\section{أدوات التحليل الإحصائي}

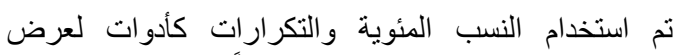

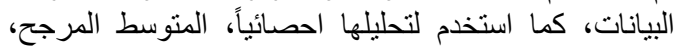

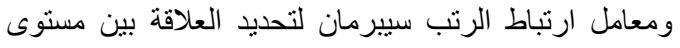

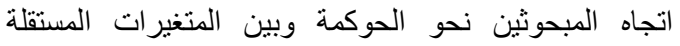

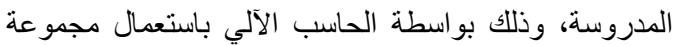
البر امج الإحصائية للعلوم الاجتماعية (SPSS).

\section{النتائج ومناقشتها}

\section{أولا: وصف عينة البحث}

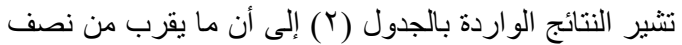

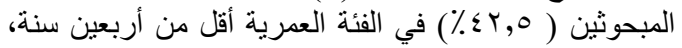

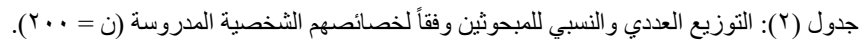

\begin{tabular}{|c|c|c|c|c|c|}
\hline$\%$ & عدد & الخصائص الثخصية & $\%$ & عدد & م الخصائص الثخصية \\
\hline \multicolumn{3}{|r|}{ حضور دورات تدريبية: } & \multicolumn{3}{|r|}{ السن: } \\
\hline r ו,0 & $4 \pi$ & نعم & $\sum Y, 0$ & 10 & \multirow{3}{*}{ 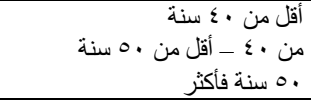 } \\
\hline$T \Lambda, 0$ & ITV & $y$ & rı, 0 & VV & \\
\hline \multicolumn{3}{|r|}{ درجة القبادية: } & $19,$. & rᄉ & \\
\hline Tr,. & $T \varepsilon$ & \multirow{2}{*}{ 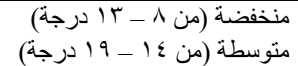 } & \\
\hline 07,0 & $11 \pi$ & & \multicolumn{3}{|r|}{ ذالنورع: } \\
\hline r ו,0 & זיד & عالية (· درجة فأكثر) & \multicolumn{3}{|l|}{07,0} \\
\hline \multicolumn{3}{|r|}{ درجة التجديدية: } & \multicolumn{3}{|r|}{ المؤهل الدر اسي: } \\
\hline $1 \cdot, \cdot$ & $r$. & منخفضة (من 9 - 10 درجة) & \multirow{5}{*}{$\begin{array}{l}r r, \cdot \\
00,0 \\
11,0\end{array}$} & \multirow{5}{*}{$\begin{array}{l}74 \\
111 \\
41\end{array}$} & \multirow{5}{*}{ مامعيط } \\
\hline$\uparrow \Lambda,$. & דזו & منوسطة (من 17 - اY درجة) & & & \\
\hline$r r,$. & $\varepsilon \varepsilon$ & عالية (r _ _ & & & \\
\hline \multicolumn{3}{|r|}{ استخدام مصادر المعلومات: } & & & \\
\hline 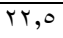 & «o & \multirow{3}{*}{ 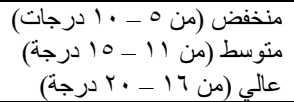 } & & & \\
\hline Tr,O & iro & & \multicolumn{3}{|r|}{ 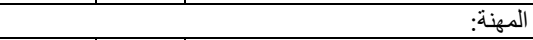 } \\
\hline $10,$. & $r$. & & \multirow{3}{*}{$\begin{array}{l}V Y, O \\
r Y, \varepsilon\end{array}$} & \multirow{3}{*}{$\begin{array}{l}100 \\
\leqslant 0\end{array}$} & \multirow{3}{*}{ مدرس } \\
\hline & & الرضنا الوظيفي: & & & \\
\hline ov, & $11 \varepsilon$ & \multirow{3}{*}{ 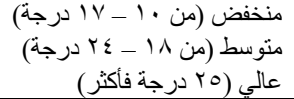 } & & & \\
\hline$\leqslant 1,0$ & Ar & & \multicolumn{3}{|r|}{ عدد سنوات الخبرة: } \\
\hline 1,0 & r & & \multirow{3}{*}{$\begin{array}{l}\leqslant \wedge, . \\
\leqslant 1, . \\
11, .\end{array}$} & 97 & \multirow{3}{*}{ 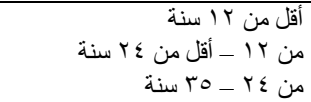 } \\
\hline & & الانفتاح على العالم الخارجي: & & Ar & \\
\hline$r_{7,0}$ & or & \multirow{3}{*}{ 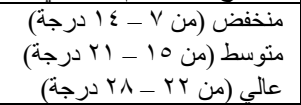 } & & rr & \\
\hline 70,0 & $1 \pi$ & & \multicolumn{3}{|r|}{ متوسط الدخل الثهري: } \\
\hline$\wedge, 0$ & IV & & \multirow{3}{*}{$\begin{array}{l}\leqslant 0,0 \\
r \wedge, .\end{array}$} & \multirow{2}{*}{$\begin{array}{l}91 \\
\text { VI }\end{array}$} & \multirow{5}{*}{ 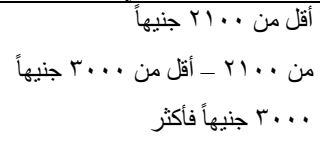 } \\
\hline & & مستوى الطموح: & & & \\
\hline $0, \cdot$ & 1. & منخفض (من آץ _ هب درجة) & & & \\
\hline$\checkmark v$, & $10 \leqslant$ & متوسط (من حr - 9 \ درجة) & 17,0 & 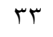 & \\
\hline $1 \wedge,$. & r & عالي (من •0 - זד درجة) & & & \\
\hline
\end{tabular}

المصدر : استمارة الاسنبيان. 
تضمن العدالة بين العاملين داخل المنظمة"، ويمكن ترتيب

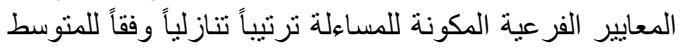

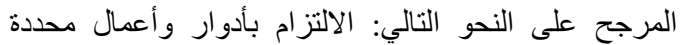

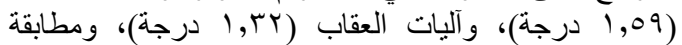

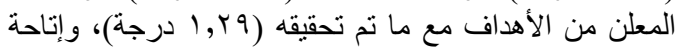

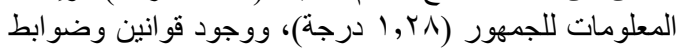

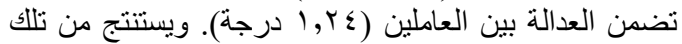

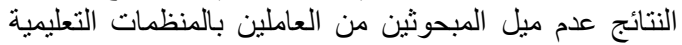

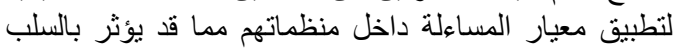

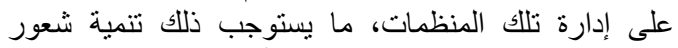

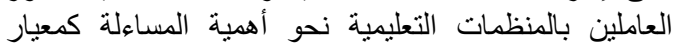
ضروري لتحسين الأداء المؤسسي. لتعية ثحو تطبيق: اتجاهات المبحوثين من العاملين بالمنظمات التعليمية

أ. الاتجاهات نحو تطبيق معيار المساعلة بالمنظمات التعليمية

أظهرت النتائج الواردة بالجدول (r) أن مستوى اتجاهات

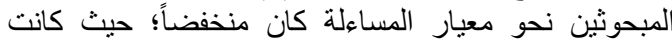

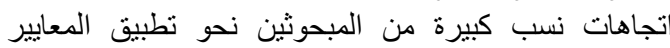

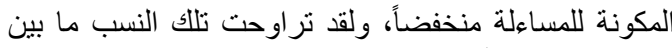

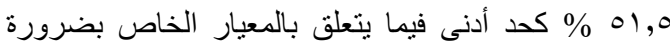

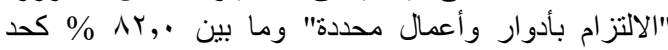

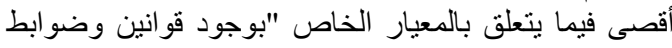

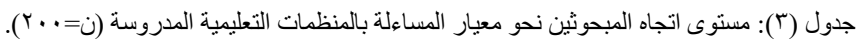

\begin{tabular}{|c|c|c|c|c|c|c|c|}
\hline \multirow{2}{*}{ المتوسط المرجح } & \multicolumn{2}{|c|}{ (^ ـ ع دالي } & \multicolumn{2}{|c|}{ (T ـ V درسطات) } & \multicolumn{2}{|c|}{ (r - منذفضة) } & \multirow{2}{*}{ المعايير الفر عية } \\
\hline & $\%$ & عدد & $\%$ & عدد & $\%$ & عدد & \\
\hline$T, r)$ & $r, \cdot$ & $\varepsilon$ & 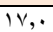 & $r \varepsilon$ & Al, , & 174 & ضرورة إتاحة المعلومات للجمهور المتردد على المنظمة \\
\hline $1, r \leqslant$ & 7,0 & 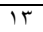 & 11,0 & Tr & Ar, & $17 \varepsilon$ & وجود قو انين وضو ابط تضمن العدالة بين العاملين \\
\hline 1,19 & $\lambda, 0$ & IV & $1 \mathrm{~T}, \mathrm{O}$ & To & $\mathrm{vq},$. & 101 & مطابقة المعلن من الأهداف مع ما تم تحقيقه \\
\hline I, Tr & $\varepsilon$, & $\mathrm{A}$ & $r \leqslant, 0$ & $\leqslant 9$ & vi,o & $1 \leqslant r$ & وضع آليات عقاب محددة \\
\hline 1,09 & 1,0 & rI & $r_{\Lambda,}$, & $\mathrm{VT}$ & 01,0 & 1.4 & الالثز ام بأدوار وأعمال محددة \\
\hline
\end{tabular}

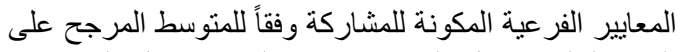

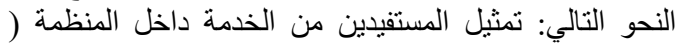

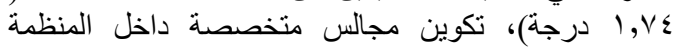

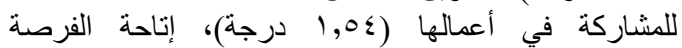

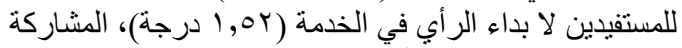

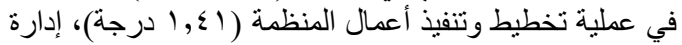

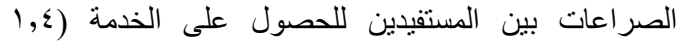

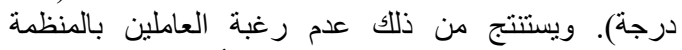

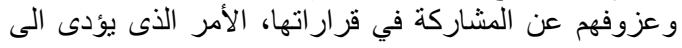

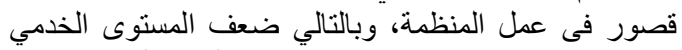

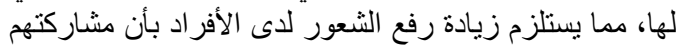

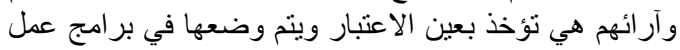
المنظمة، وذللك كوسيلة لجذب العاملين ولين الى المشاركة في في

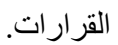

ب. الاتجاهات نحو تطبيق معيار المشاركة بالمنظمات التعليمية

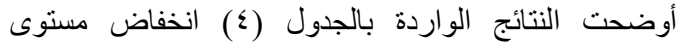

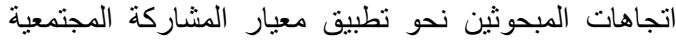

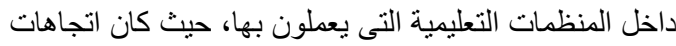

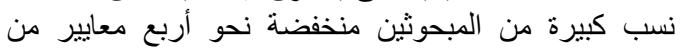

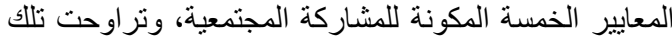

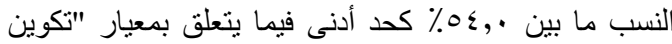

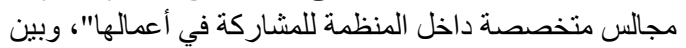

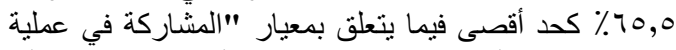

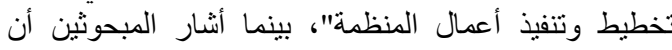

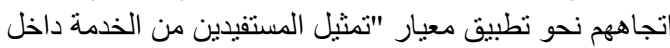

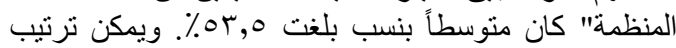

جدول (§): مستوى اتجاهات المبحوثين نحو معيار المشاركة بالمنظمات التعليمية المدروسة (ن=. • †).

\begin{tabular}{|c|c|c|c|c|c|c|c|}
\hline \multirow[t]{2}{*}{ 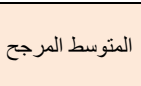 } & \multicolumn{2}{|c|}{ (^ ـ ع درجات) } & \multicolumn{2}{|c|}{ 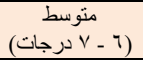 } & \multicolumn{2}{|c|}{ (r - منفضضة) } & \multirow{2}{*}{ المعايير الفرعية } \\
\hline & $\%$ & عدد & $\%$ & عدد & $\%$ & عدد & \\
\hline $1, \vee \varepsilon$ & $1 ., 0$ & r) & or,o & $1 . \mathrm{V}$ & $r \bar{r},$. & VT & تمثيل المستفيدين من الخدمة داخل المنظمة \\
\hline $1, \varepsilon$ & $\varepsilon, 0$ & 9 & ri,. & Tr & $7 \leqslant, 0$ & $1+9$ & إدارة الصر اعات بين المستفيدين للحصول على الخدمة \\
\hline $1,0 \mathrm{r}$ & $\Lambda, \cdot$ & 17 & $r \bar{r}, \cdot$ & VY & $04,$. & $\pi r$ & إتاحة الفرصة للمستفبدين لا بداء الرأي في الخذمة \\
\hline $1,0 \leqslant$ & $\lambda, \cdot$ & 17 & $r \Lambda,$. & $\mathrm{VT}$ & $0 \leqslant,$. & 1.1 & تكوين مجالس متخصصة داخل المنظمة للمشار كة في أعمالها \\
\hline $1, \Sigma 1$ & 7,0 & $\pi$ & $r \wedge,$. & 07 & 70,0 & $1 \pi 1$ & المشاركة في عملية تخطيط وتنفيذ أعمال المنظمة \\
\hline
\end{tabular}

المصدر: استمارة الاستبيان. 


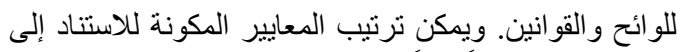

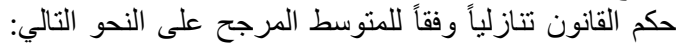

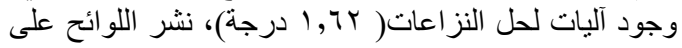

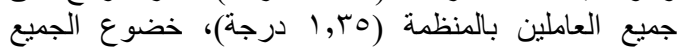

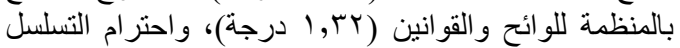

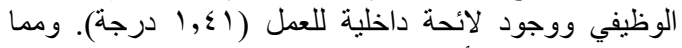

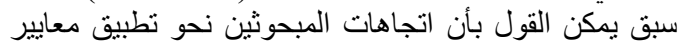

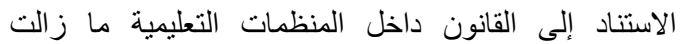

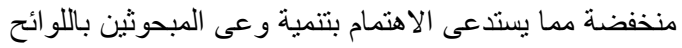

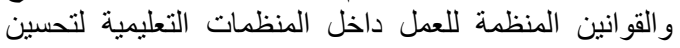
اتجاهات المبحوثين نحو تلك المعايير.
جالم. الاتجاهات نحو تطبيق معيار الاستناد إلى حكم القانون بالمنظمات التعليمية

أفادت النتائج الواردة بالجدول (0) أن مستوى اتجاهات

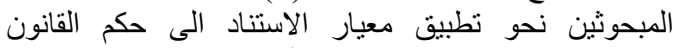

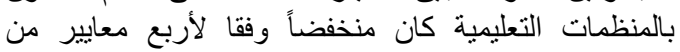

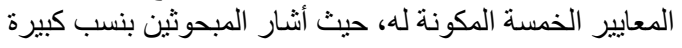

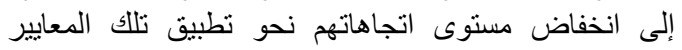

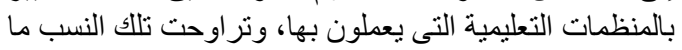

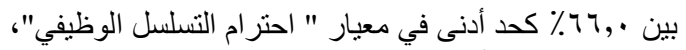

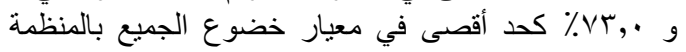

جدول (0): مسنوى اتجاهات المبحوثين نحو معيار الاستتاد إلى حكم القانون بالمنظمات التعليمية المدروسة (ن= · ب).

\begin{tabular}{|c|c|c|c|c|c|c|c|}
\hline \multirow{2}{*}{ المتوسط المرجح } & \multicolumn{2}{|c|}{ 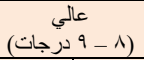 } & \multicolumn{2}{|c|}{ 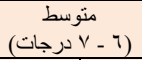 } & \multicolumn{2}{|c|}{ منخفض (T - مدرجة) } & \multirow{2}{*}{ المعايير الفرعية } \\
\hline & $\%$ & عدد & $\%$ & عدد & $\%$ & عدد & \\
\hline $1, \leqslant 1$ & $\wedge, \cdot$ & 17 & YO,0 & 01 & $77, \cdot$ & $1 \pi$ & احتر ام التسلسل الوظيفي \\
\hline $1, \leqslant 1$ & $\mathrm{v}, \mathrm{O}$ & 10 & KY, & or & 77,0 & 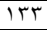 & وجود لائحة داخلية للعمل \\
\hline 1, ro & $0, \cdot$ & $1 \cdot$ & ro,. & 0. & $\mathrm{v \cdot , \cdot}$ & $1 \leqslant \cdot$ & نشر اللو ائح على جميع العاملين بالمنظمة \\
\hline $1, r+4$ & 0,0 & 11 & $r 1,0$ & $\leqslant T$ & $V T, \cdot$ & $1 \leq 7$ & خضوع الجميع بالمنظمة للو ائح و القو انين \\
\hline $1,7 Y$ & $\mathrm{v}, \cdot$ & $1 \leqslant$ & $\varepsilon \wedge, \cdot$ & 97 & $\leqslant 0$, & 9 . & وجود آليات لحل النز اعات \\
\hline
\end{tabular}

المصدر: استمارة الاستبيان.

بتحديث المعلومات على شبكة الإنترنت، ويمكن ترتيب

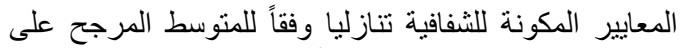

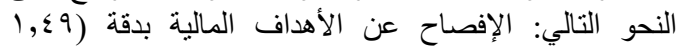

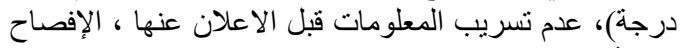

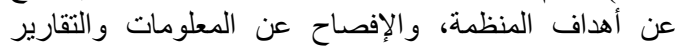

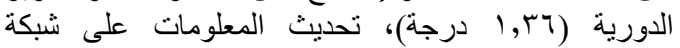

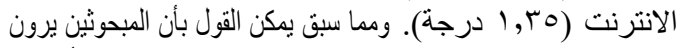

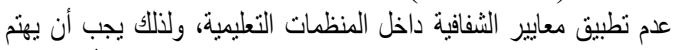

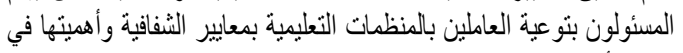
تحسين أداء المنظمة.

\section{د. اتجاهات المبحوثين نحو معيار الثفافية داخل المنظمات التعليمية المدروسة أمبوتة}

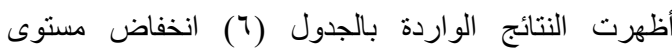

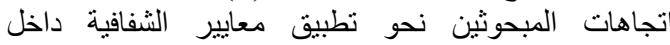
المنظمات التعليمية التى يعملون بها، حيث كانت نسئ نسب كبئ ديبرة

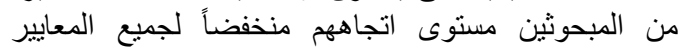

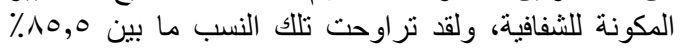

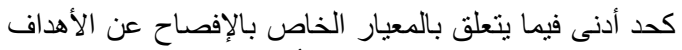

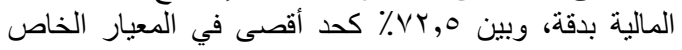

جدول (ך): مستوى اتجاه المبحوثين نحو معيار الثفافية بالمنظمات التعليمية المدروسة (ن= · †).

\begin{tabular}{|c|c|c|c|c|c|c|c|}
\hline \multirow[t]{2}{*}{ 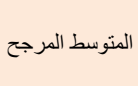 } & \multicolumn{2}{|c|}{ 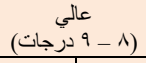 } & \multicolumn{2}{|c|}{ 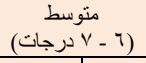 } & \multicolumn{2}{|c|}{ (r _- منفضة) } & \multirow{2}{*}{ المعايير الفرعية } \\
\hline & $\%$ & عدد & $\%$ & عدد & $\%$ & عدد & \\
\hline $1, \leqslant 9$ & $\mathrm{v}, \mathrm{o}$ & 10 & $r \leqslant, \cdot$ & 71 & 01,0 & $11 \mathrm{~V}$ & الإفصاح عن الأهداف المالية بدقة \\
\hline $1, \pi$ & $\varepsilon, \cdot$ & $\Lambda$ & $r \Lambda, \cdot$ & 07 & $\uparrow \wedge, \cdot$ & $1 \times 4$ & الإفصاح عن أهداف المنظمة \\
\hline 1,47 & $r, \cdot$ & 7 & $r \cdot, 0$ & 71 & 77,0 & $1 \mathrm{Tr}$ & عدم تسريب المعلومات قبل الاعلان عنها \\
\hline 1,47 & 7,0 & ir & $r \mu, 0$ & $\sum v$ & $\overline{V \cdot, \cdot}$ & $1 \leqslant$. & الإفصاح عن المعلومات و التقارير الدورية \\
\hline 1,40 & $\mathrm{v}, \mathrm{o}$ & 10 & $T \cdot, \cdot$, & $\varepsilon$. & $V Y, O$ & $1 \leqslant 0$ & تحديث المعلومات على شبكة الانترنت. \\
\hline
\end{tabular}

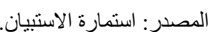

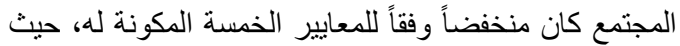

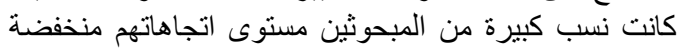

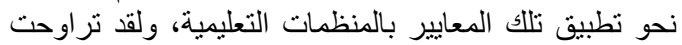

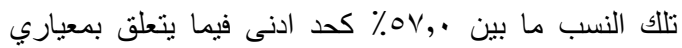
التفاعل مع مشكلات المواطنين بمختلف فئاتهم، واحترام بنئ
هـ. اتجاهات المبحوثين نحو معيار الاستجابة والتوافق حول مصالح المجتمع بالمنظمات التعليمية المدروسة الانجة

أظهرت النتائج الواردة بالجدول (V) أن مستوى اتجاه

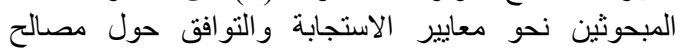


نتيجة لاتفاقيات متبادلة (• ع, ا درجة)، تلبية القرار لحاجات

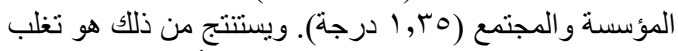

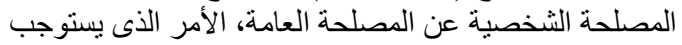

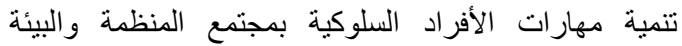

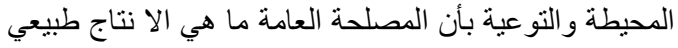
لمجمو عة من المصالح الفردية.

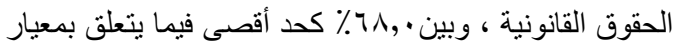

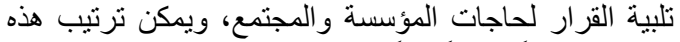

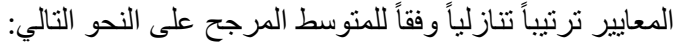

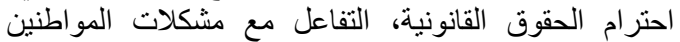

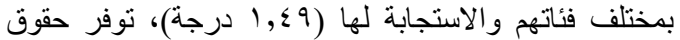

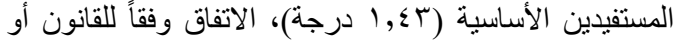

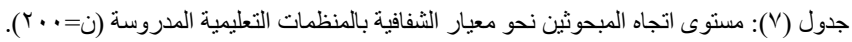

\begin{tabular}{|c|c|c|c|c|c|c|c|}
\hline \multirow[t]{2}{*}{ المتوسط المرجح } & \multicolumn{2}{|c|}{ 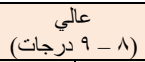 } & \multicolumn{2}{|c|}{ 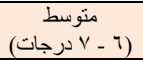 } & \multicolumn{2}{|c|}{ (r) من م درجة) } & \multirow{2}{*}{ المعايير الفرعية } \\
\hline & $\%$ & ع عدد & $\%$ & عدد & $\%$ & عدد & \\
\hline $1, r_{0}$ & $r, 0$ & $\mathrm{~V}$ & $r \wedge, 0$ & ov & $7 \wedge$, & 1147 & تلبية القرار لحاجات المؤسسة والمجتمع \\
\hline $1, \varepsilon r$ & $7, \cdot$ & IT & ri,. & 74 & $4 \pi$, & $1+7$ & توفر حقوق المستفيدين الأساسية \\
\hline $1, \varepsilon \cdot$ & $0, \cdot$ & 1. & $r \cdot, 0$ & 71 & $7 \varepsilon$, & 149 & التعامل وفقاً للقانون أو نتيجة لاتفاقيات متبادلة \\
\hline $1, \leqslant 9$ & $7, \cdot$ & IT & $r v, \cdot$ & $V \varepsilon$ & ov,. & $11 \varepsilon$ & التفاعل مع مشكلات المو اطنين بمختلف فئاتهم و الاستجابة لها \\
\hline $1, \leqslant 9$ & $7, \cdot$ & ir & $r v, \cdot$ & $V \leqslant$ & ov, & $11 \leqslant$ & احتر ام الحقوق القانونية \\
\hline
\end{tabular}

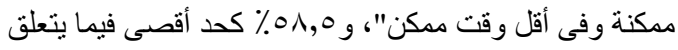

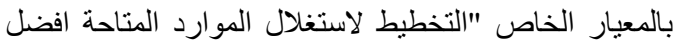

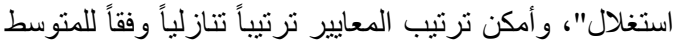

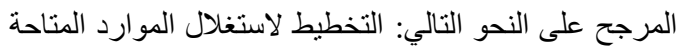

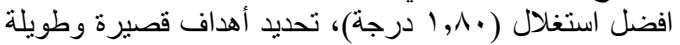

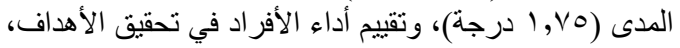

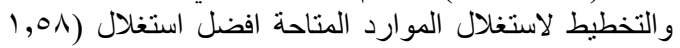

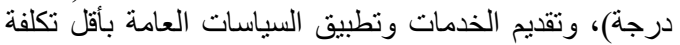

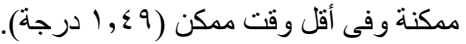

\section{و. اتجاهات المبحوثين نحو معيار الكفاءة والفعالية داخل المنظمات التعليمية المدروسة المبن}

أظهرت النتائج الواردة بالجدول (^) أن مستوى اتجاه

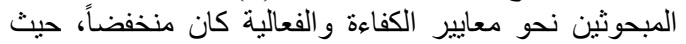

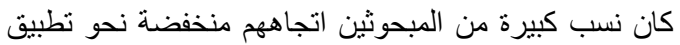

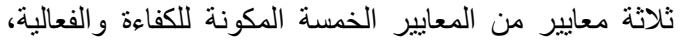

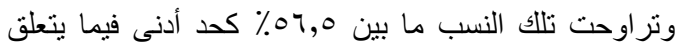
بمعيار "تقديم الخدمات وتطبيق السياسات العامة بأقل تكلفة

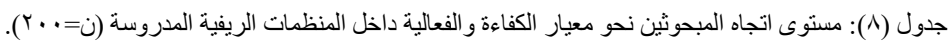

\begin{tabular}{|c|c|c|c|c|c|c|c|}
\hline \multirow{2}{*}{ المتوسط المرجح } & \multicolumn{2}{|c|}{ (^ ـ ع درجات) } & \multicolumn{2}{|c|}{ 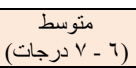 } & \multicolumn{2}{|c|}{ (r - منفض درجة) } & \multirow{2}{*}{ المعايير الفر عية } \\
\hline & $\%$ & عدد & $\%$ & عدد & $\%$ & عدد & \\
\hline $1, \times 0$ & $1 \wedge, 0$ & $\mu \nu$ & ro,. & v. & $\$ 7,0$ & 94 & تحديد أهداف قصبرة وطويلة المدى \\
\hline $1, \wedge$. & Tr,O & ¿० & ro,o & VI & $\varepsilon \uparrow,$. & $\wedge \varepsilon$ & حسن استغلال المو ارد البشرية و المادية من قبل المنظمة لتلبية الاحتياجات المحددة \\
\hline 1,01 & 10,0 & ri & $r V, O$ & 00 & ov, & $11 \leqslant$ & تقييم أداء الأفر اد في تحقيق الأهداف \\
\hline 1,01 & 17,0 & Tr & TO,. & 0. & $0 \wedge, 0$ & $11 \mathrm{~V}$ & التخطيط لاستغلال الموارد المتاحة افضل استغلال \\
\hline $1, \leqslant 9$ & $1 .,$. & r) & $r \Lambda,$. & 07 & 07,0 & TK & تققيم الخدمات وتطبيق السياسات العامة بأقل تكلفة ممكنة وفى أقل وقت ممكن \\
\hline
\end{tabular}

المصدر: استمارة الاستبيان.

أظهرت النتائج الواردة بالجدول (9) أن مستوى اتجاه

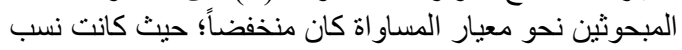

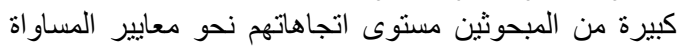

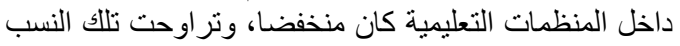

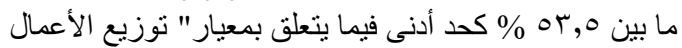

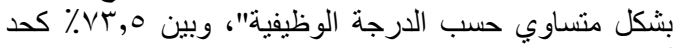

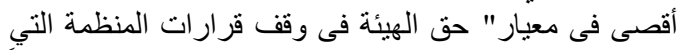

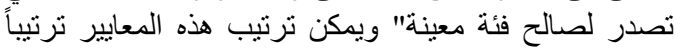

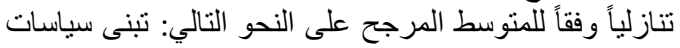

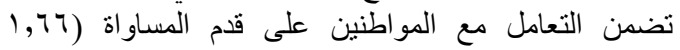

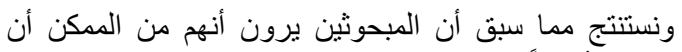

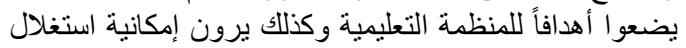

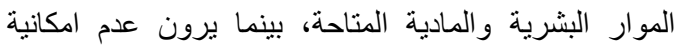

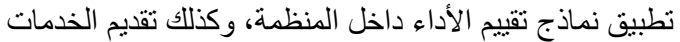

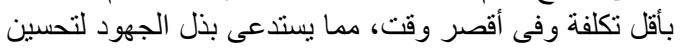

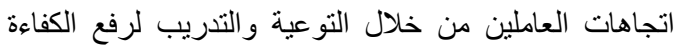
و الفعالية للمنظمة التعليمية.

ز. اتجاهات المبحوثين نحو معيار المساواة بالمنظمات التعليمية المدروسة 


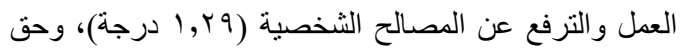
الهيئة في وقف فر ار الت المن المنظمة التي تصدر لصالح فئة معينة

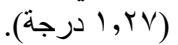

درجة)، وتوزيع الأعمال بشكل منساوي حسب الدرجة

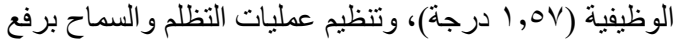
دعاوى جماعية من قبل المنظمة (1, (1, درجة)، ومئه وممارسة

جدول (9): مستوى اتجاه المبحوثين نحو معيار المساو اة داخل المنظمات التعليمية المدروسة (ن=. +Y).

\begin{tabular}{|c|c|c|c|c|c|c|c|}
\hline \multirow[t]{2}{*}{ المتوسط المرجح } & \multicolumn{2}{|c|}{ 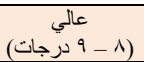 } & \multicolumn{2}{|c|}{ 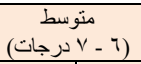 } & \multicolumn{2}{|c|}{ منخفض (r - مدرة) } & \multirow{2}{*}{ المعايير الفرعية } \\
\hline & $\%$ & ع عدد & $\%$ & عدد & $\%$ & عدد & \\
\hline $1, r V$ &., 0 & 1 & rq,. & or & $V r, 0$ & $1 \leqslant V$ & حق الهيئة وقف قرارات المنظمة الني تصدر لصالح فئة معينة \\
\hline $1,0 \mathrm{r}$ & 9,0 & 19 & 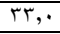 & 77 & $0 \vee, 0$ & 110 & تنظيم عمليات التظلم و السماح برفع دعاوى جماعبة من قبل المنظمة \\
\hline $1,0 \mathrm{~V}$ & $1 \cdot, 0$ & Y) & rч, & VY & Or,o & $1 \cdot v$ & توزيع الأعمال بشكل منساوي حسب الدرجة الوظيفية \\
\hline 1,77 & Ir, & $T \leq$ & $\varepsilon r, \cdot$ & $\Lambda \varepsilon$ & $\pi r, \cdot$ & 94 & تبنى سباسات تضمن التعامل مع المو اطنين على قدم المساو اة \\
\hline 1,19 & $\mathrm{~V}, 0$ & 10 & $r \cdot, 0$ & 71 & $T Y, \cdot$ & 94 & ممارسة العمل و الترفع عن المصالح الشخصية \\
\hline
\end{tabular}

المصدر: استمارة الاستيبان.

اتجاهات المبحوثين السلبية نحو معايير الحوكمة، الأمر الذى دإي

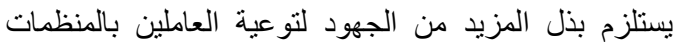

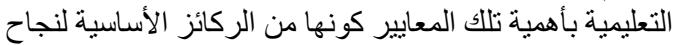
هذه المنظمات في تأدية رسالتها.

رابعا: العلاقة الارتباطية بين اتجاهات المبحوثين نحو معايير

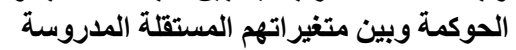

أوضحت النتائج الموضحة بالجدول (11) وجود علاقة ارتباطية طردية بين اتجاهات المبحوثين لتطبيق معايير

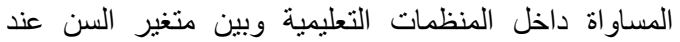

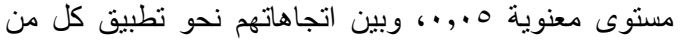

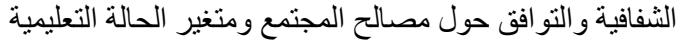

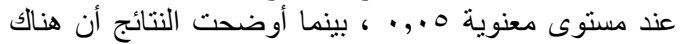
علاقة عكسية بين اتجاهات المبحوثين نحو تطبيث معائي دايير

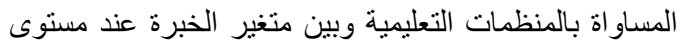

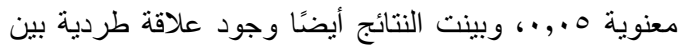

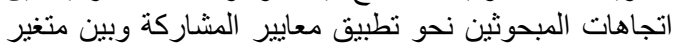

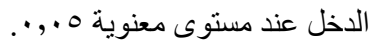

ثالثا: المستوى الإجمالي لاتجاهات المبحوثين نحو معايير الحوكمة بالمنظمات التعليمية المدروسة الإنماتية

أظهرت النتائج الواردة بالجدول ( • (1) أن اتجاهات المبحوثين

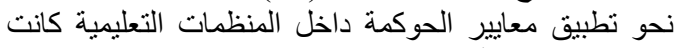

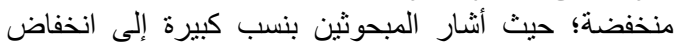
مستوى اتجاهاتهم نحو تطبيق أربعة معايير من المعايير السبعة

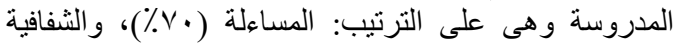

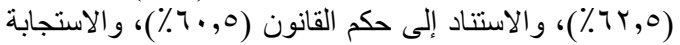

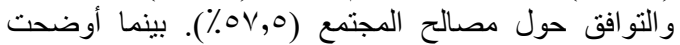

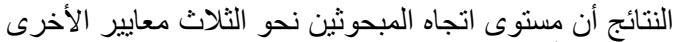

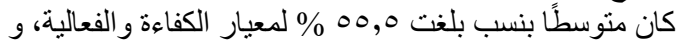

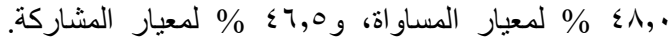

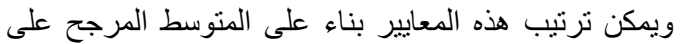

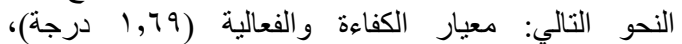

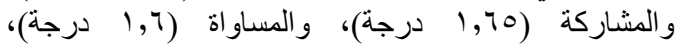

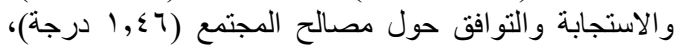

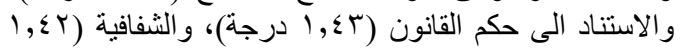

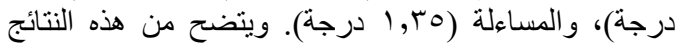

جدول (• (1): اتجاهات المبحوثين نحو معايير الحوكمة داخل المنظمات التعليمية المدروسة (ن= · ·r).

\begin{tabular}{|c|c|c|c|c|c|c|c|}
\hline \multirow{2}{*}{ المتوسط المرجح } & \multicolumn{2}{|c|}{ (זr - •r دالي جات) } & \multicolumn{2}{|c|}{ 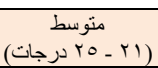 } & \multicolumn{2}{|c|}{ 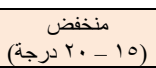 } & \multirow[t]{2}{*}{ مستوى الاتجاه } \\
\hline & $\%$ & عدد & $\%$ & عدد & $\%$ & عدد & \\
\hline $1, r_{0}$ & 0,0 & 11 & $T \leqslant, 0$ & $\sum 9$ & $\overline{v \cdot, \cdot}$ & $1 \leqslant$. & المساءلة \\
\hline 1,70 & 9,0 & 19 & $\leqslant 7,0$ & 94 & $\varepsilon \varepsilon$, & $\Lambda \Lambda$ & المشاركة \\
\hline $1, \varepsilon$ & $\varepsilon, \cdot$ & $\Lambda$ & $r o, 0$ & V) & $7 ., 0$ & $T \pi$ & الاستتاد إلى حكم القانون \\
\hline $1, \leqslant \mathrm{r}$ & $\varepsilon, \cdot$ & $\Lambda$ & $r \leqslant, \cdot$ & 71 & $T, \cdot$ & IrE & الثفافية \\
\hline $1, \leqslant 7$ & $\varepsilon, \cdot$ & $\Lambda$ & $r \Lambda, 0$ & VV & $0 \mathrm{OV}, \mathrm{O}$ & 110 & الاستجابة و التو افق حول مصالح المجتمع \\
\hline 1,79 & $\mathrm{v}, \cdot$ & $1 \varepsilon$ & 00,0 & 111 & $r v, 0$ & vo & الكفاءة و الفعالية \\
\hline 1,7 & $7, \cdot$ & it & $\{\wedge$, & 97 & $\leqslant 7, \cdot$ & 94 & المساو اة \\
\hline
\end{tabular}

المصدر: استمارة الاستيبان. 
Salem et al. / Archives of Agriculture Sciences Journal 4(2) 48-60, 2021.

جدول (1 (1): معاملات ارتباط الرتب (سييرمان) بين مستوى اتجاهات المبحوثين نحو معايير الحوكمة ومتغير اتهم المستقلة المدروسة.

\begin{tabular}{|c|c|c|c|c|c|c|c|}
\hline \multicolumn{7}{|c|}{ معامل ارتباط سبيرمان } & \multirow[t]{2}{*}{ المعايير - ت كاير } \\
\hline المساواة & الكفاءة والفعالية & التو افق حول مصالح المجنمع & الثفافية & الاستجابة للقانون & المشاركة & المساءلة & \\
\hline$* ., .99$ &., .7 &.,., $1 \Gamma_{-}$ & ., &.,.$r \varepsilon$ & $\cdot, \ldots \Lambda_{-}$ &.,. $\mathrm{TV}$ & 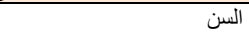 \\
\hline.,.$\wedge 7$ & $\frac{., \cdot V T}{V T}$ & $*,, I Y)$ & $* ., 111$ & $\cdot, \cdot, 11$ & $\cdot, \cdot r$. &., .70 & الحالة التعليمبية \\
\hline$* ., 1,9_{-}$ &., $.0 \mathrm{~V}$ & $\cdot, \cdot, Y \varepsilon_{-}$ &., .1 &., .19 &., .70 &.,.$r$. & الخبرة \\
\hline.,$\ldots 0$ &.,.$\times 9_{-}$ &., .00 &.,.$\times 1$ & $\cdot, \cdot \leqslant \wedge$ & $*,, .9 \leqslant$ & $\cdot, \cdot, \varepsilon 0$ & الدخل \\
\hline., . YO &., $.0 \mathrm{~V}$ &., .10 &., .10 & $*,, 11 \varepsilon$ & $* *,, r \cdot \varepsilon$ & $* *,, 1 \uparrow \lambda$ & 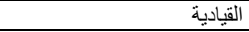 \\
\hline.,$\ldots r$ &.,$+Y \wedge$ & (ז., &.,.,$r$. & $* ., 9 \lambda$ & $*, ., 14$ &.,., $\mathrm{~V}$ & التجديدية \\
\hline$* *,, Y, Y$ & $* * ., 1 \leqslant 1$ & $* ., 99$ & $* *,, 17 \pi$ & **.,YTY & $1, \cdot$ & $\cdot,, \ldots \varepsilon$ & استخدام مصادر المعلومات \\
\hline$* *,, 11 \leqslant$ & $* *,, \cdot \wedge 9$ & $* *,, 19 Y$ & **.,ITr & **.,r.r & $* ., 1,9$ & $* * ., 190$ & الرضا الوظيفي \\
\hline **.,,$\uparrow \wedge$ & $* * ., 191$ & **., Iro &.,$\cdot \wedge r$ & $*,, 1, Y$ & **, ,YYY & **., $10 \mathrm{Y}$ & الانفتاح \\
\hline$*,, 174$ & ., & $*_{,}, .9 Y$ & $* *,, 1 \leqslant 7$ &., .79 & $\cdot, \cdot \vee \vee \wedge$ &., .17 & الطموح \\
\hline
\end{tabular}

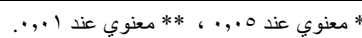

Y. ت تعزيز المشاركة المجتمعية داخل المنظمات

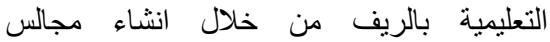

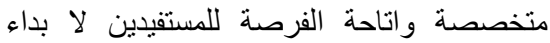

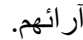
الاهتمام بتطبيق نماذج تقييم الأداء داخل المنظمة،

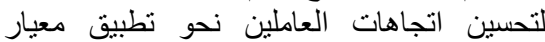
الكفاءة والفعالية داخل المنظمات التعليمية بالريف.

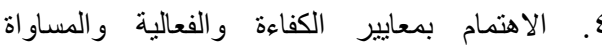

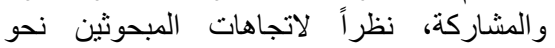
تطبيقها متوسط مما يعنى استعدادهم لتطبيقها داخل

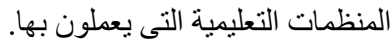

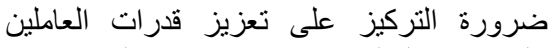
بالمنظمات التعليمية وخاصة فيما يتعلق بقدرتهم

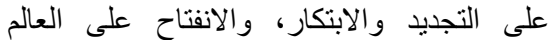

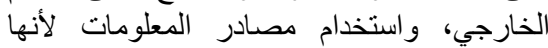
مستقبلا لها تأثير إيجابي على توجئ توجه العاملين لتطبيق معايير الحوكمة. الجراء المزيد من الدراسات للتعرف على على أسباب

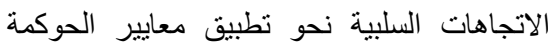

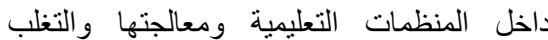
عليها.

\section{قائمة المراجع}

\section{مراجع باللغة العربية}

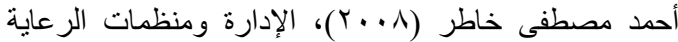

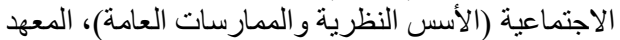

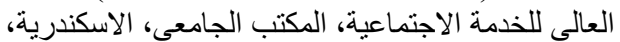

$$
\text { جمهورية مصر العربية. }
$$

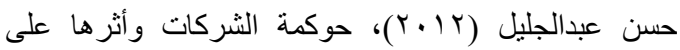
مستوى الافصاح في المعلومات المحاسبية، رسالة ركاتة
وأظهرت النتائج أيضًا وجود علاقة ارتباطية طردية بين اتجاهات المبحوثين نحو تطبيق معايير المساءلة والمشاركة

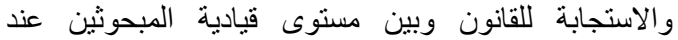

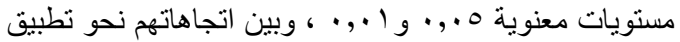

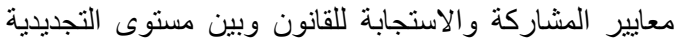

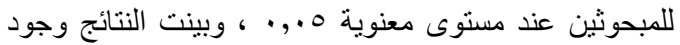

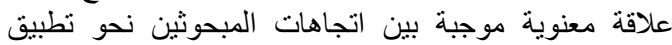

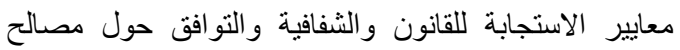

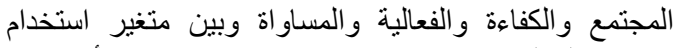

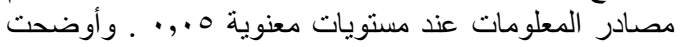

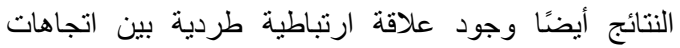

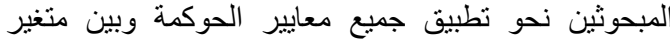

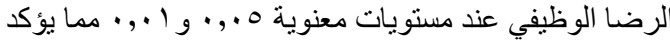
أهمية الرضا الوظيفي عند تطبيق معايير الحوكمة داخل المنظمات التعليمية. وكذلك بين اتجاهاتهم نحو تطبيق جميع المعايير فيما عدا الثفافية وبين متغير الانفتاح على التين العالم

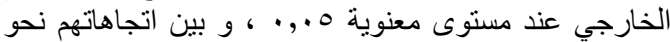

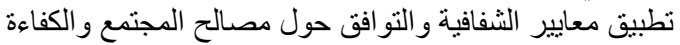

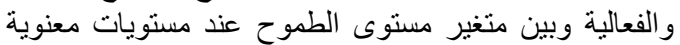

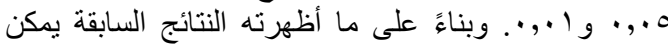

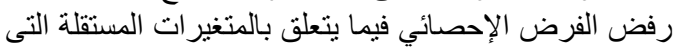

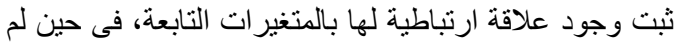

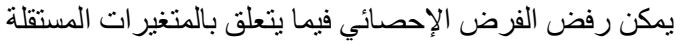

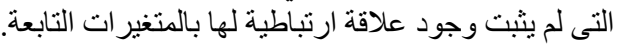

\section{توصيات البحث}

بناء على النتائج التى تم التوصل اليها من البحث يمكن الخروج

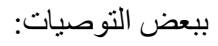

ا . ضرورة تتمية وعى العاملين بالمنظمات التعليمية

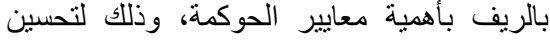
اتجاهاتهم نحو تطبيقها داخل منظماتهم. 


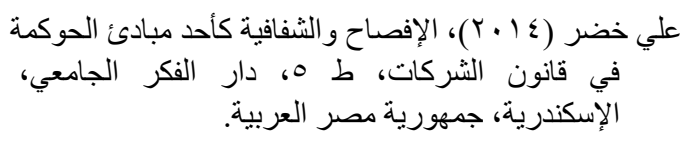

ماهر أحمد حسن محمد (10 ب ب)، حوكمة مؤسسات التعليم قبل فيل

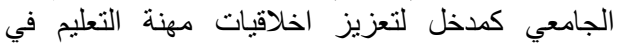

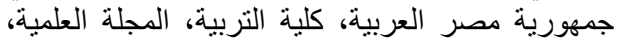

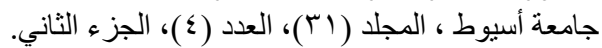

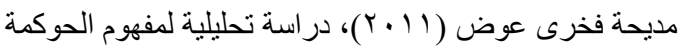

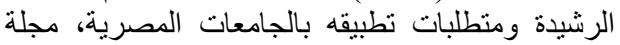

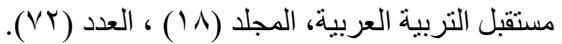

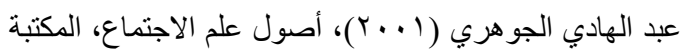

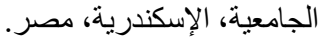

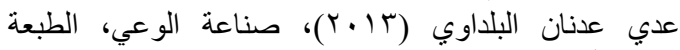
الأولى، مؤسسة البلداوي للطباعة، العر اق.

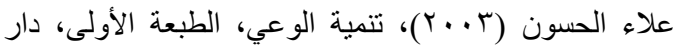
الغدير للطباعة و النشر، إير ان. تلني

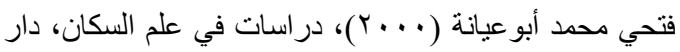
النهضة العربية للطباعة و النشر ، بيروت، لبنات فينان.
ماجستير، غير منشورة، كلية الادارة والاقتصاد، الأكاديمية العربية، الدنمارك.

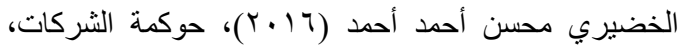
مجموعة النيل العربية، القاهرة، جمهورية مصر العربية.

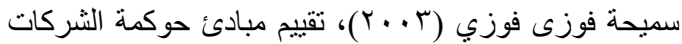

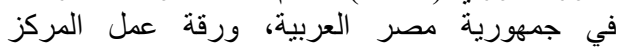

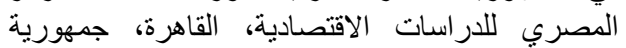

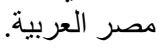

عبد المجيد الصلاحين (•l (ب)، الحوكمة في المؤسسات

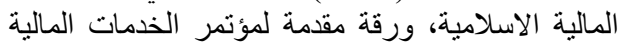
الاسلامية الثاني، طر ابلس، ليبيا.

عديلة مصطفى العدمات (7 ( ب)، التدقيق الداخلي في إطار

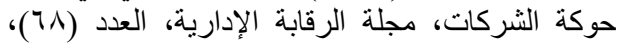
يونيو، القاهرة، جمهورية مصر العربية.

عطوة محمد محمد (؟ ا.ب)، حوكمة النظام التعليمي مدخل

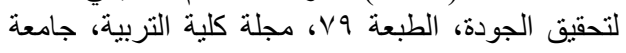
المنصورة، الجزء الثاني، جمهورية مصر العربة العربية.

\section{مراجع باللغة الانجليزية}

Halleck, J. and Poisson, M. (2006), Governance in Education: transparency and Accountability, UNESCO, Paris, France. 